\title{
Defining and Formalising Project Management Models and Processes
}

\author{
Ravinder Singh ${ }^{1}$, Dr. Kevin Lano ${ }^{2}$ \\ Research Scholar, Department of Informatics, King's College, London, UK ${ }^{1}$ \\ Reader, Department of Informatics, King's College, London, $\mathrm{UK}^{2}$
}

\begin{abstract}
The research is aimed at studying the feasibility of defining/ formalising model driven project management with base methodology of PMBOK. Our research focuses on PMBOK since more than $75 \%$ of the projects around the world use PMBOK for managing projects. Previous research works had considered one or two areas of Project Management but did not consider the whole methodology, and also did not make use of model driven methods. Our research is proposing a model driven project management using UML and OCL for all the 5 process areas and 10 knowledge areas of the PMBOK. The research work will provide large scale applications of system modelling. This will provide support of defining tools for Project Management, deliverables, and documentation. These models will provide consistency, enhance the reusability of components, reliability, and help in automation of standard processes of Project Management.
\end{abstract}

Keywords: Modelling; Programme and project Management Distributed work; Onshore; Offshore; Software; IT projects, Automation, Software Engineering.

\section{INTRODUCTION}

Projects, Programmes, Portfolios are taken at all levels of organisation which may be involving one or many units and they can involve one or 100 s of persons. The duration of projects can vary from few weeks to many years. Projects can be simple to highly complex projects, which may be implemented at one location or multiple locations across multiple countries.

Project Management (PM) in broader context means programme management, practice management, portfolio management, Project management office, etc. Project management system is a set of tools, techniques, methodologies, resources, and procedures used to manage a project. This research is an attempt to create a hierarchy of plan, analyse, design, build, test, deploy and various risk, quality and configuration requirements to address project management.

This aim is to help project managers have models which can be used to generate various deliverables, documentation and aids like PM plan, network diagram, risk plans, communication plans, scope, etc. These models will facilitate in organising project activities effectively for efficient management of projects. This will also provide large scale applications of systems modelling.

Considering PMBOK standard as base because majority of projects use PMBOK, meta-models will be defined for the process and knowledge management areas. The benefits of having meta-models would include the following:

- Support for defining tools for project management, deliverables and documentation, and to improve consistency between different areas and processes of PMBOK.
- Reusability of tools, documents and deliverables.

- Consistency and reliability in the management of various projects.

- Easier project monitoring and controlling for the execution and full life cycle of the project.

- The final advantage will come in the form of delivering good quality project on time, budget and scope with improved quality.

- Overall customer satisfaction as risk and issues would be managed efficiently and effectively.

- Automation of project management standard process.

Projects are considered at all levels of organisation which may involve one or many business units and they can involve one or 100s of persons. The duration of projects can vary from a few weeks to many years.

Projects can be simple to highly complex projects, which may be implemented at one location or multiple locations across multiple countries.

This work has been applied to a software project for a large financial institution. The project was completed on time and on budget and the major achievement was that project had gone live on the promised date.

The client observed that there were some projects which finished close (2-3 weeks late) to the planned date but not on the same date as mentioned in the project management plan. The project has been a great success as the modelling helped to create good project management plan taking into consideration PMI guidelines and was managed effectively and efficiently. 


\section{OVERVIEW OF RELATED RESEARCH}

Project management is a very complex field and encompasses technical skills along with man management skills to manage stakeholder expectations. Projects are influenced by both internal and external factors and require various communication channels and techniques to reduce the gap and deliver project effectively and efficiently.

According to Project Management Body of Knowledge (PMBOK) [1], a project is a temporary endeavour undertaken to create a unique product, service or result. PMBOK describes project management as accomplished through the application and integration of five project management processes: Initiating, Planning, Executing, Monitoring and Controlling, and Closing. PMBOK also defines project management into nine knowledge areas. Project management is the application of knowledge, skills, tools and techniques to meet project requirements. Project managers have to manage the so called Triple constraints - "Scope, Time, and Cost", which have been enhanced in recent time with three more constraints called "Quality, Risk and Customer Satisfaction".

We have presented various papers [4-7] based on our research work and literature survey conducted to understand research and development work being undertaken in the field of Project Management.

The studies have been conducted to understand the existing standard models [8-12] and adapt them so as to manage projects in a better way. Modifications have been suggested so as to make existing methodologies work in different areas of work. The studies showed that different methodologies could be suitable for different types of projects. It has also been proposed that tailoring of methodologies would be more useful for different scenarios providing efficient and effective project management and control. The studies also showed that large complex system can be better managed and controlled by dividing the system into smaller modules or phases.

System modelling, dynamic modelling, estimation models and object oriented modelling concepts have been investigated for improving project management [13-16]. The studies showed that system modelling would be useful to have better communication among different stakeholders by managing various communication means, channels and modes. The studies showed that risks could be forecasted and managed more effectively by the use of dynamic modelling. The studies also showed that object oriented modelling concepts and properties like inheritance, modularity, data-encapsulation, relations could be used to describe the life cycle of the projects and manage it more efficiently. The studies proposed a mathematical model for estimating and forecasting along with the use of iterative development for better monitoring and control of the project.

Software and ICT projects have their own challenges due to rapid technological advances, providing better services, facilities etc. Therefore, standard project management methodologies only may not be sufficient for managing project in this area. These methodologies may have to enhance and that's the reason that Agile, JAD, RAD, extreme programming have been developed [17-26]. The studies also showed that project management methodologies/ models should be customised/ tailored for the different projects so as to best fit the scenario and hence avoid unnecessary details and reduce cost and time. The studies also tried to combine different methodologies and framework like RUP, PMBOK, agent framework, metaphors and graphical presentations for creating new frameworks/ models to suit the requirements for managing, controlling, and execution of the project successfully within time and budget. The studies demonstrated that better estimates could be achieved and also stakeholders could manage in a better manner for overall success of the project. The studies also showed that quality control tools/ methodologies like ISO, CMMI would be highly useful in delivering good quality projects. Stakeholders have different set of obligations, constraints, necessities, and expectations as projects in R\&D organisations are knowledge intensive requiring more sharing of ideas. These differences have been highlighted in the research papers [27-28]. The studies showed that knowledge sharing areas/ sites for the researchers to share/ propose/ discuss their ideas by using blogs, discussion groups, and chat rooms would be highly useful to enhance creativity and innovations.

Researchers had been able to study various project management methodologies, tools, and techniques etc. empirically and statistically [29-36]. The studies showed that various factors like Management commitment, financial constraints, organisational structure, reward system, education and training of project teams play a crucial role in the successful management of projects. The project managers also tailor their methodology to suit the needs to reduce the cost and time for delivering the projects. The studies also proposed that scope and change management training would be highly useful to project managers for executing, monitoring, and controlling the projects successfully. The studies also showed that in new dynamic environment newer technologies would be more useful than traditional models of development and management of projects. Various techniques like critical path method, PERT, baselining, scope, change, and risk management would be of great help for successful delivery and management of the projects.

They had collected data from various projects to study different areas of project management and analysed it for understanding the effectiveness of various models, techniques or tools. Use of alternative statistical techniques and models such as Fuzzy Logic, NPV, approach-avoidance theory, had been explored in the project management area [37-42]. The studies showed that techniques like NPV, fuzzy logic would be highly useful in estimating and forecasting the project execution with better monitoring and control of the projects. The studies also showed that decision tree analysis, fishbone or cause-effect diagrams could be used effectively to manage quality, risks and deliver successful projects. Project 
managers need different skills/ tools/ techniques / methodologies to manage various projects efficiently.

Leadership abilities, communication and management abilities along with IQ, EQ, and MQ of the project manager have a huge impact on projects [43-46]. Teaching of project management is not only about just teaching of GANTT and PERT chart but also must include various software and other tools for successfully managing projects. The studies have shown that project managers should use various communication tools/ methods with different stakeholders. Project managers should have the qualities to be a good team player, manager, having the ability to take decisions with responsibility to deliver successful projects. The studies showed that project manager should be able to manage the expectation of team members, motivating them, understand their training needs and communicate with them at different levels so to manage various stakeholders, teams in a better manner and make them more productive.

Distributed environment of projects in the present multinational organisations gives rise to more complexities in all areas of project management [47-70]. Therefore, standard project management methodologies have to be enhanced to meet diverse requirements from various stakeholders. The studies showed that distributed work environment has its own challenges and advantages. The challenges could be such as managing different time zones, cultural differences, virtual communication environments and costs associated with them, and many more. The advantages could be in terms of providing good quality projects at lower cost. This requires proper documentations, setup the correct expectations, managing various stakeholders and also managing the cross cultural issues effectively and efficiently. The conflict resolution criterion and transparent communication is the key to success in global scenarios and managing successful projects.

Maturity level is able to give the reliability of organisation in a particular area [71-80]. There are a number of maturity and capability levels for project management such as (PM) $)^{2}$, OPM3, CMMI, IEEE, etc. against which an organisation can be appraised. The maturity models take into account PM processes, factors and characteristics and shows the organisation's progress from functional to project driven organisation. The maturity models describe how mature the processes are, the success rate of the organisation in past, and also the probability that it would be able to deliver good quality projects. The organisation could use these models to build robust processes and also optimise them with feedback and changing scenarios and environment.

We also studied various other work-flows and methodologies like SPEM, BPMN, Petri-Nets [88-98]. They have their own limitations and complexities due to their own notations and symbols to be used for modelling PMBOK.

Since PMBOK is the recognised (de facto) standard of project management, research would be used to propose a model using UML and OCL for PMBOK processes and knowledge management areas. The model based approach would help to provide benefits of reusability, consistency, and better reliability of the project delivery.

\section{OBJECTIVES OF PROJECT MANAGEMENT}

The main objective of Project Management is to manage the processes defined in the project plan. This involves managing the project risks and issues to ensure that the project meets the business objectives and stakeholder expectations in a coordinated and timely manner and satisfies formal reviews and sign-offs.

Project management should ensure that stakeholders' concerns are acknowledged and appropriately addressed and provide the necessary support to enable stakeholders to meet the project goals.

PM should be able to balance scope, quality, effort, schedule, budget, and risks at all times. PM has to identify the appropriate solution and risk mitigation strategies using standards, documented decision analysis and resolution processes when the projected impact of an issue or a risk exceeds the project threshold.

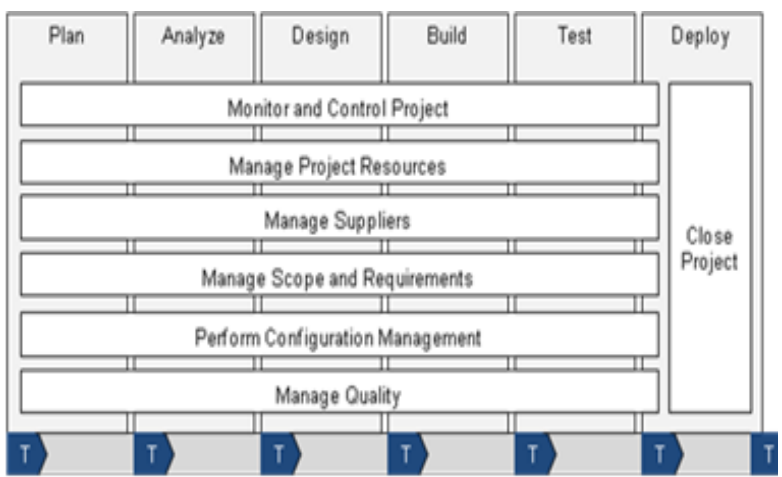

Fig. 1. Project Management

As shown in Fig. 1 above, PM has to ensure that the project methods, standards, and approaches are followed and facilitate deliverable transitions between project life cycle stages and ensure that key project deliverables are effectively transitioned and placed under configuration management.

PM should implement quality management process such as process and product quality assurance (PPQA) and other quality-related reviews (e.g., Quality and Process Improvement or best practice reviews). On completion of project PM should transfer responsibility for ongoing maintenance to the appropriate entity.

\section{PROJECT MANAGEMENT PROCESS GROUPS}

The PMI [1] standard describes the nature of project management processes in terms of integration between the processes, the interactions within them, and the purpose they serve. Process is a set of interrelated actions and activities that are performed to achieve a pre-specified set of products, results, or services. PMI groups various processes of project management into five groups, i.e. Initiating Process Group, Planning Process Group, Executing Process Group, Monitoring and Controlling Process Group, and Close Process Group. 
Even though the project management processes are process in sufficient detail that gaps in particular projects presented as discrete elements, but they overlap and can be identified (either manually, or preferably, by a project management professionals can manage the project project management tool). In addition to the models, we in different ways. The objectives of the projects can be provide an index and cross-reference for the models, defined based on the complexity, risk, size, time, which identifies for each entity, which model creates resources, documents, deliverables, application area, instances of the entity, and which models then read geographic spread, experience, and maturity of team and instances of the entity. This allows the dependencies organisation. The concept of interaction and overlapping between models to be traced.

of PM processes can be traced to Plan-Do-Check-Act Further applications of our models may also be possible, (PDCA) cycle.

The Planning Process Group corresponds to "Plan" component of PDCA, the Executing Process Group corresponds to "Do" component of PDCA, the Monitoring and Controlling Process Group corresponds to "Check and Act" component of PDCA as shown in Fig. 2 below:

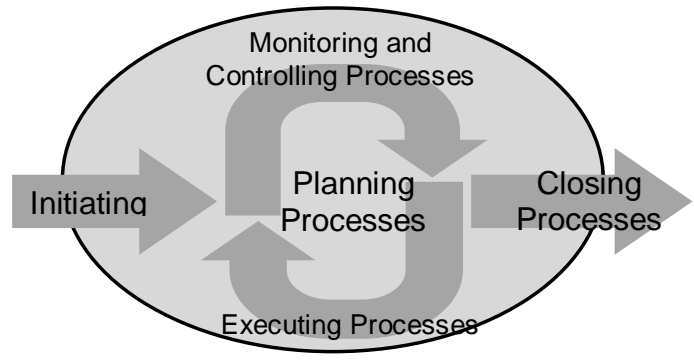

Project Management Process Groups mapped to the PDCA Cycle (Plan-Do-Check-Act) -

Fig. 2. PM Processes mapped to PDCA Cycle

PMI further divides the project management into nine knowledge areas which are Project Integration Management, Project Scope Management, Project Time Management, Project Cost Management, Project Quality Management, Project Human Resources Management, Project Communications Management, Project Risk Management, Project Procurement Management and Project Stakeholder Management.

\section{MODEL DRIVEN BUSINESS PROCESS ENGINEERING/ UML-RSDS}

MBE encompasses software engineering approaches using models to support analysis, design and implementation of software systems. Models include models of entities and relationships, such as UML class diagrams, and behavioral models, such as statecharts. In our work, we are interested in using models to (i) make precise the concepts of PMBOK, to express inter-relationships between these concepts, and to support precise comparison of the PMBOK elements to the artifacts produced by a specific project management process; (ii) to specify the data and functionality of automated tools to support a PMBOK management process.

We therefore use UML class diagrams, at the application level, to define our models of PMBOK data and operations. These models can be used to help project managers follow the PMBOK process in a rigorous manner. They can also specify the PMBOK data and for example, to enable the definition and automated collection of metrics about a project management process.

\section{WHAT PART OF PMBOK WILL BE MODELLED?}

We will use a formalisation and model based on the mapping of Project Management Process groups and knowledge areas as per PMBOK 5th edition is as shown in Table-1 and the activity diagram shown in Fig. 3 to evaluate the case studies and the effectiveness of our approach to identify the gaps between the model and the projects/ case studies.

This would help us to map the model/ formalisations based on the PMBOK 5th edition and apply it to the case study/ projects for evaluation.

\section{Table-1: Project Management Process Group and} Knowledge Area Mapping:

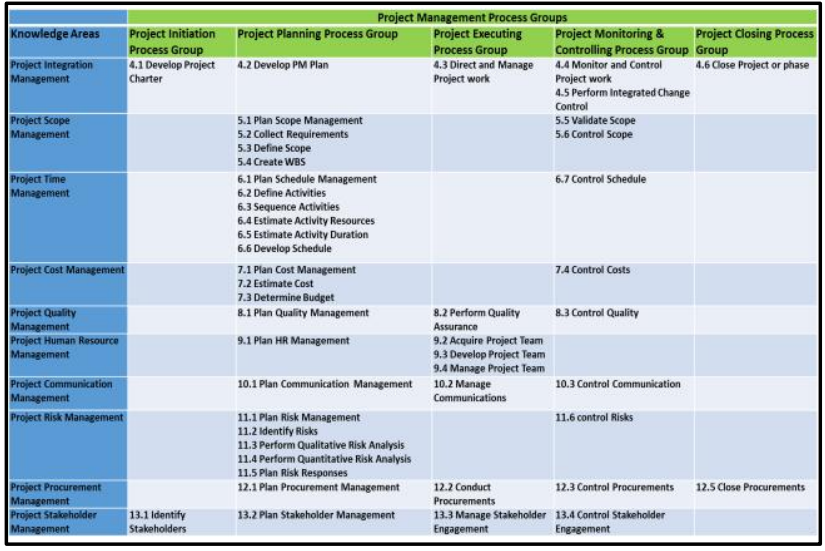

The detailed process chart based on various activities to be performed as per PMBOK $5^{\text {th }}$ edition for the overall project management process groups is given in Fig 3. The lists of activities to be performed in various Process Management Groups are listed as under:

\subsubsection{Initiating Process Group}

- Select a Project Manager

- Determine Company Culture \& Existing System

- Collect Processes and Historical information

- Divide large project into phases

- Identify Stakeholders

- Document business needs

- Determine project objective

- Determine Assumptions and constraints 
- Develop Project Charter

- Develop Preliminary Project Scope Statement

\subsubsection{Planning Process Group}

- Determine how you will do planning - part of management process

- Create Project Scope Statement

- Determine Team

- Create WBS and WBS dictionary

- Create Activity List

- Create Network Diagram

- Estimate Resource Requirements

- Estimate Time and Cost

- Determine Critical path

- Develop Schedule

- Develop Budget

- Determine Quality, Standards, Processes, \& Metrics

- Determine Roles and Responsibilities

- Determine Communication requirements

- Risk Identification, Qualitative and Quantitative Risk Analysis \& Response planning

- Iterations - Go back

- Determine what to purchase

- Prepare Procurement documents

- Finalize the "How to Execute \& Control" aspects of the management plans

- Create Process Improvement plan

- Develop final PM Plan \& Performance Measurement Baselines

- Gain Formal Approval

- Hold Kick-off meeting

\subsubsection{Executing Process Group}

- Acquire Final Team

- Execute the PM Plan

- Complete Product Scope

- Recommend Changes \& Corrective actions

- Send and Receive Information

- Implement approved changes, defect repair, preventive and corrective actions.

- Continuous Improvement

- Follow Processes

- Team Building

- Give Recognition and Rewards

- Hold progress meetings

- Use work authorization system

- Request Seller Response

- Select Sellers

\subsubsection{Monitoring and Controlling Process Group}

- Measure against the Performance Measurement Baselines

- Measure according to the management plan

- Determine variances, and if they warrant corrective action or a change

- Scope Verification

- Configuration Management

- Risk Audits
- Recommend changes, defect repair, preventive and corrective actions

- Integrated change control

- Approve changes, defect repair, preventive and corrective actions

- Manage reserves

- Use Issue logs

- Facilitate conflict resolution

- Measure team member performance

- Report on performance

- Create forecasts

- Administer Contracts

\subsubsection{Closing Process Group}

- Develop Closure procedures

- Complete Contract Closure

- Confirm work is done to requirements

- Gain formal acceptance of the product

- Final performance reporting

- Index archive records

- Update Lessons Learned knowledge base

- Hand off completed product/ project

- Release resources

The activity workflows which would be followed for linking the project management process, knowledge areas and deliverables to be created as per the PMBOK 5th edition is given below in Fig 3. The purpose of the models is to provide a specification of PMBOK, which is also a specification to support PMBOK project managers should follow. The use is to specify the PMBOK data and process in sufficient detail that gaps in particular projects can be identified (either manually or preferably, by a management support tool).

\section{ACTIVITY DIAGRAM FOR PROJECT MANAGEMENT PROCESS GROUPS}

The activities diagram for project management processes groups as given by PMBOK, $5^{\text {th }}$ edition (PMI, USA) is depicted in the Fig. 3 below:

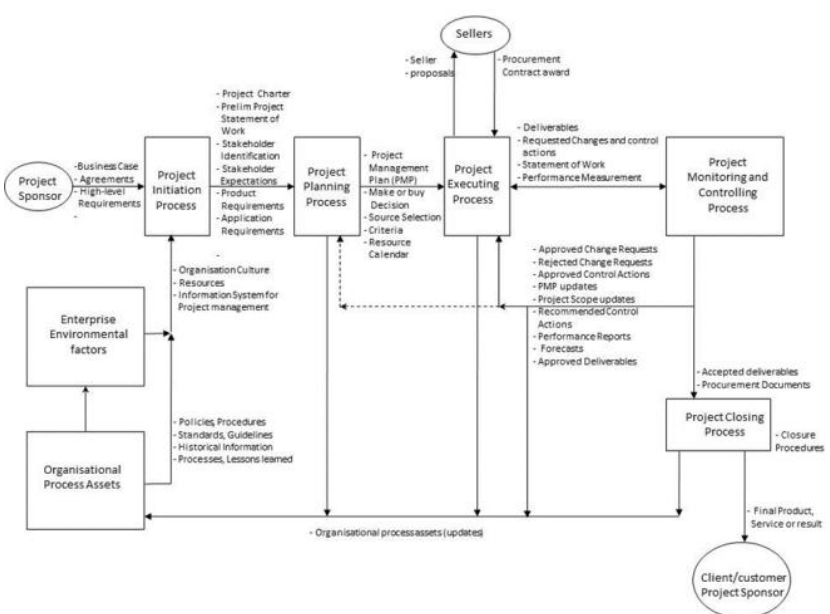

Fig. 3. Activity Diagram for high level process interactions (from PMBOK, $5^{\text {th }}$ edition) 
Once the project is sponsored by the client/ customer, the project initiation process is started, which helps to create documentation such as Project Charter, Preliminary Project Statement of Work based on various objectives, constraints, assumptions, organisation culture and enterprise environmental factors.

The project enters the plan phase and the Project Management Plan is created which defines the overall programme schedule, budget, timelines, resources, performance measurement baselines, risk and issues management, quality, communication management and change management plans.

The project is then executed and managed with monitor and control processes. The project is tracked and the deliverable are checked as per the measurement parameters and statement of work. Various changes are managed as the plan is defined and once the deliverables are approved, the project is handed over to the client and closed while creating a lesson learned log.

We have specified and created formalised models for all the PMBOK Process Management Groups and Knowledge Areas. In this paper we present example specifications of one process group and one knowledge area.

\section{PROJECT CLOSING PROCESS GROUP}

The closing processes include various activities to close and finish the project. The team hands off the completed project or product to the appropriate stakeholders or close a cancelled project.

The project is completed as per the acceptance criterion defined in the project management plan. The final reports are generated and lesson learned $\log$ is created. The project resources are released. The main objectives of the project closing are given below:

- Close out the completed project, and evaluate its overall results.

- Ensure all project activities have been completed.

- Finalize all documentation, and transfer responsibility to the new responsible parties.

- Release all resources.

- Perform process improvement activities: conduct project review meetings, document lessons learned, harvest knowledge assets and submit the assets to organization-wide repositories for reuse.

Project is to be closed once the acceptance criteria are met and the project is delivering the required performance. Stakeholders give their approval for the closure of the project. A final report is written and lesson learned log is created for the future projects to learn from the current project and will serve as reference. The resources are released so that they are available to work on new projects. Fig 4 shows our formalisation if the Project Closing Process Group data and operations.

Closure class has an association with ClosureProcedure(CP) class through the Closure Procedure. The Project is closed by performing the tasks in ClosetheProject() operation and then releasing the resources as defined in the ReleaseResources() operation.

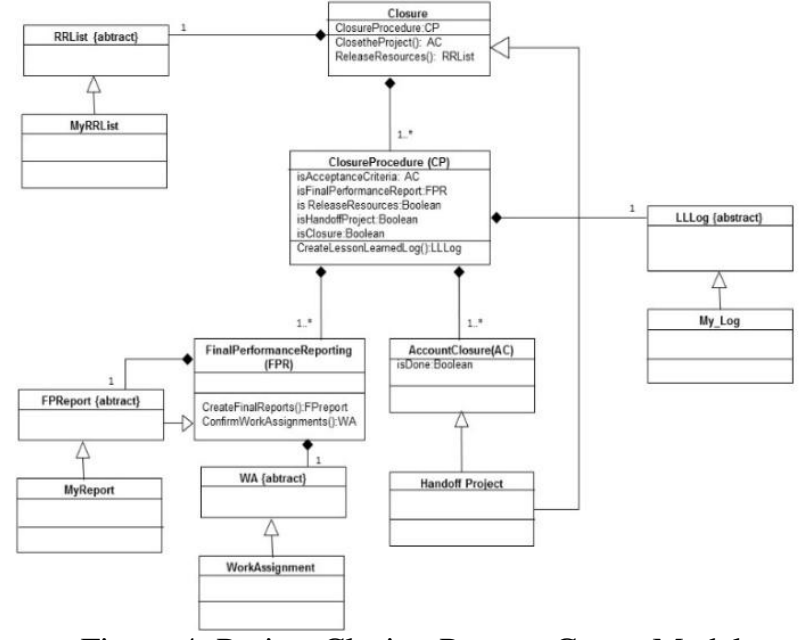

Figure 4: Project Closing Process Group Model

The ClosureProcedure(CP) class has the attributes of is AcceptanceCriteria: which is used to evaluate the project against approved criterion for completion. The criterion could be based on the project deliverables, change and transformation processes implemented, application, or system delivered. Stakeholders approve the project once the task has been completed as per the laid down criteria of Cost, time, scope, quality, etc.

The attribute isFinalPerformanceReport is associated with FinalPerformanceReporting(FPR) class which is used to perform two operations of generating final reports using CreateFinalReports() and confirming that the work has been completed as per the expectations and approved criterion using the method ConfirmWorkAssignments().

When the project has been completed and handed over to the client and the client signs off the project, the resources are released and the project is closed.

Use the LessonLearnedLog() operation to identify the deliverables to be harvested, cleansed (as needed), and posted to the knowledge management repository. Project evaluation data (actuals vs. estimates) is documented in the project estimating group for integration into the estimating model.

The project manager should do the followings:

- Identify the key artifacts that can be shared. This could include the estimation model, project plans, development strategy, Risk Log, Best Practices, metrics etc.

- Review these artifacts for suitability.

- If the organization has a Process Improvement team or a Software Engineering Process Group (SEPG) or knowledge management team, submit the artifacts to this group.

\begin{tabular}{|l|l|}
\hline $\begin{array}{l}\text { PMBOK[1] processes and } \\
\text { activities (section) }\end{array}$ & Formalised Model \\
\hline $\begin{array}{l}\text { Administrative Closure } \\
\text { Procedure (3.7.1) }\end{array}$ & $\begin{array}{l}\text { Closure class Closure } \\
\text { Procedure class } \\
\text { ClosetheProject } \\
\text { operation }\end{array}$ \\
\hline $\begin{array}{l}\text { Hand off completed product, } \\
\text { service, or result (3.7.1, }\end{array}$ & $\begin{array}{l}\text { isHandoffProject } \\
\text { attribute }\end{array}$ \\
\hline
\end{tabular}


International Journal of Advanced Research in Computer and Communication Engineering

Vol. 5, Issue 6, June 2016

\begin{tabular}{|l|l|}
\hline 3.7.2) & \\
\hline $\begin{array}{l}\text { Confirm work is done to } \\
\text { requirements (3.7.1) }\end{array}$ & $\begin{array}{l}\text { isAcceptanceCriteria } \\
\text { attribute }\end{array}$ \\
\hline $\begin{array}{l}\text { Contract Closure procedure } \\
\text { (3.7.2) }\end{array}$ & $\begin{array}{l}\text { AccountClosure (AC) } \\
\text { class }\end{array}$ \\
\hline Release Resources (3.7.1) & $\begin{array}{l}\text { ReleaseResources } \\
\text { operation }\end{array}$ \\
\hline $\begin{array}{l}\text { Final Performance } \\
\text { Reporting (3.7.1) }\end{array}$ & $\begin{array}{l}\text { CreateFinalReports } \\
\text { operation }\end{array}$ \\
\hline $\begin{array}{l}\text { Update Knowledge } \\
\text { Management database } \\
\text { (3.7.1) }\end{array}$ & $\begin{array}{l}\text { Create } \\
\text { LessonLearnedLog } \\
\text { operation }\end{array}$ \\
\hline
\end{tabular}

Various steps which could be followed for completing the above processes are described in details below:

\section{$>$ ClosureProcedure}

This list helps close out project operation and transition the appropriate management details to the client or application management team.

\begin{tabular}{|l|l|}
\hline $\begin{array}{l}\text { Administrative Closure } \\
\text { Procedure (3.7.1) }\end{array}$ & $\begin{array}{l}\text { Closure class } \\
\text { ClosureProcedure } \\
\text { class } \\
\text { ClosetheProject } \\
\text { operation }\end{array}$ \\
\hline $\begin{array}{l}\text { Hand off completed product, } \\
\text { service, or result (3.7.1, 3.7.2) }\end{array}$ & $\begin{array}{l}\text { isHandoffProject } \\
\text { attribute }\end{array}$ \\
\hline
\end{tabular}

\section{$>$ ClosetheProject}

- Understand policies for closing project.

- Prepare a back-up and archival plan.

- Prepare for packaging project knowledge assets and experiences to be contributed to the Knowledge Exchange, capability group, methodology group, etc.

- Confirm deliverable ownership and a deliverable transition plan.

- Approach the appropriate organization contact to complete the closing activity such as legal and commercial, finance, human resources, etc.

- Prepare a closure presentation for the client's management team.

- Confirm the plan and schedule for project closure activities.

- Ensure all sponsors and stakeholders agree to the signoff checklist.

- Confirm the metrics that the project must achieve before transfer is accounted for.

- Confirm the transition of all reporting, planning, and metrics tracking.

- Document and obtain approval from the client on what formal acceptance of the application means.

- Confirm adherence to the current company retention policy.

- Leverage the records lead at the program level.

- Clear any retention policy changes with the company's legal department.

- Validate that the client agreed with the retention policy.
- Confirm adherence to the company's vaulting/ archiving approach.

\begin{tabular}{|l|l|}
\hline $\begin{array}{l}\text { Confirm work is done } \\
\text { to requirements (3.7.1) }\end{array}$ & $\begin{array}{l}\text { ConfirmWorkAssignments } \\
\text { () operation }\end{array}$ \\
\hline
\end{tabular}

\section{$>$ ConfirmWorkAssignments}

- Identify any type of warranty support required after transitioning the application.

- Confirm agreement to IP rights.

- Confirm your third party release approach to minimize penalties.

- Confirm the terminations of rental or lease agreements

- Confirm deliverable ownerships.

- Obtain agreement on all transitioned deliverables.

- Walk through the transitioned deliverables and turnover ownership.

\begin{tabular}{|l|l|}
\hline $\begin{array}{l}\text { Contract Closure } \\
\text { procedure (3.7.2) }\end{array}$ & $\begin{array}{l}\text { AccountClosure (AC) } \\
\text { class }\end{array}$ \\
\hline
\end{tabular}

\section{AccountClosure}

- Determine and document who the client contacts with questions after transitioning the application.

- Determine and document who is responsible for periodic relationships and meetings to continue client relationships.

- Retain or dispose of archives and records in compliance with contractual obligations and applicable legal and regulatory requirements, such as tax or data privacy laws, which may vary by jurisdiction.

\begin{tabular}{|ll|l|}
\hline $\begin{array}{l}\text { Release } \\
(3.7 .1)\end{array}$ & Resources & $\begin{array}{l}\text { ReleaseResources() } \\
\text { operation }\end{array}$ \\
\hline
\end{tabular}

\section{$>$ ReleaseResources}

- Communicate roll-off dates at least two weeks prior to the actual roll-offs.

- Update the Roll-on/Roll-off Form with the roll-off information

- Complete performance reports for all personnel.

- Release third party resources.

- Return or remove hardware and software, as appropriate.

- Return any leased or rented items or services. Terminate all associated agreements.

- Confirm release of all resources with appropriate reviews.

\begin{tabular}{l|l|} 
Update Knowledge & $\begin{array}{l}\text { CreateLessonLearnedLog() } \\
\text { Management database } \\
\text { operation } \\
\text { (3.7.1) }\end{array}$
\end{tabular}

\section{CreateLessonLearnedLog}

- Submit time tracking data to the standard estimating tool used to generate the original project estimates. Submit these time tracking actuals to the estimating tool owner. 
- Ensure completion of metrics collection in the project measurement reporting tool.

- Package and post project initiation documents such as the proposal(s) and Business Case.

- Package and post the client's requirements document. Consider including documents such as data flow diagrams, entity relationship diagrams, and a data dictionary.

- Package and post plan documents such as the Project Plan, Configuration Management Plan, Work Plan, Risk Management Plan, Project Communications Plan, Quality Management Plan, and any technical plans created.

- Package and post high-level design documents such as the conceptual design, database design, functional design, technical architecture design, and project standards.

- Package and post detailed design documents such as the flow/structure charts, pseudo-code, and program specification documents.

- Package and post source code and any other files and utilities required to create the development environment.

- Package and post-test documents such as the test plans, test approaches, test data, stubs, dummy programs, test scripts and scenarios, and test results.

- Package and post the product selection documents.

- Package and post the acceptance procedures for delivery, installation, and acceptance.

- Package and post manuals such as user manuals, installation manuals, and operations manuals.

- Package and post any other documents of interest the project management team deems potentially helpful to similar future projects.

\begin{tabular}{|l|l|}
\hline Final Performance & $\begin{array}{l}\text { CreateFinalReports() } \\
\text { operation }\end{array}$ \\
\hline
\end{tabular}

\section{CreateFinalReports}

- Communicate the project's requirements, and confirm if those requirements were met.

- Communicate the planned vs. actual schedule and costs, as appropriate.

- Communicate on the client's and our expectations, and confirm if those expectations were met.

- Communicate the major challenges, how they were overcome, and the major successes realized.

- Document the general and process-related information, including overall productivity achieved, quality delivered, processes used, process deviations, estimated and actual start and stop dates, and tools used on the project.

- Document the size and effort, including the number and complexity of software modules, peak number of FTEs, and duration in total hours, calendar days, and person-days.

- Document a summary of the defects found during the project.
- Document the causal analysis, which may lead to process improvements or be recorded as lessons learned.

- Document the knowledge assets that contributed to the organization. They are artifacts that may be useful for future projects.

\section{OBJECT/ INSTANCE OF THE PROJECT CLOSING PROCESS GROUP}

Please find below one of the instances of the Project Closing Process Group:

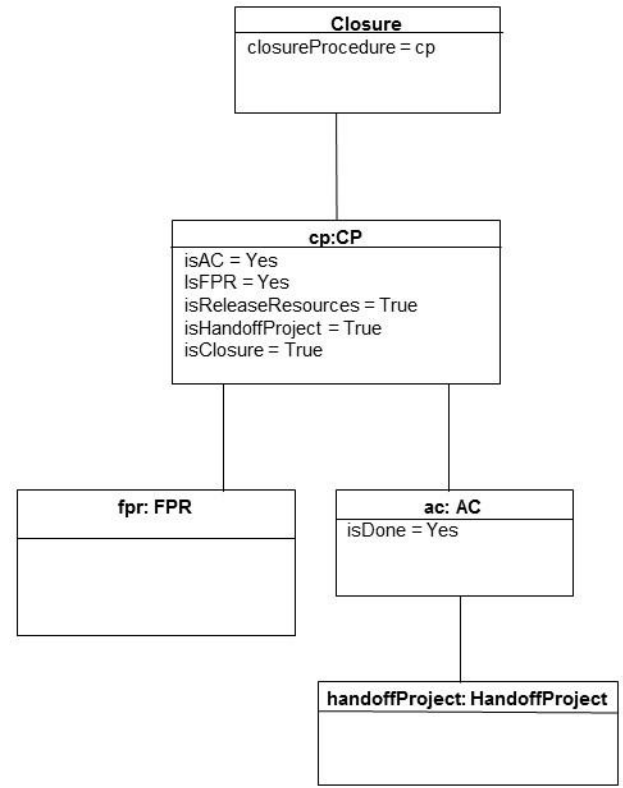

Figure 5: Object Model of Project Closing Process Group

\section{PROJECT MANAGEMENT KNOWLEDGE AREAS}

PMBOK[1] defines the Knowledge Area as a complete set of concepts, terms, and activities that make up a professional field, project management field, or area of specialisation. PMBOK[1] divides the project management into ten Knowledge Areas.

- Project Integration Management,

- Project Scope Management

- Project Time Management

- Project Cost Management

- Project Quality Management

- Project Human Resources Management

- Project Communications Management

- Project Risk Management

- Project Procurement Management

- Project Stakeholder Management

Even though PMBOK [1] have presented them as different processes with defined interfaces but in practice these areas are interrelated, and they overlap and operate in different ways which are not be completely possible/ feasible to capture or describe in PMBOK Guide. 
We have formalised all of the Knowledge Areas of PMBOK [1]. We give an example of one formalised model in this section.

\section{PROJECT STAKEHOLDER MANAGEMENT}

This defines the processes for managing stakeholders and understanding their expectations and managing them effectively. The objectives of the stakeholder management are as follows:

- Identify the project's decision makers and major influences.

- Understand the new application's business rationale.

- Confirm the target business processes.

- Confirm what the key sponsor, users, and other stakeholders want to achieve from the new application.

- Understand and create Stakeholder Expectations Matrix

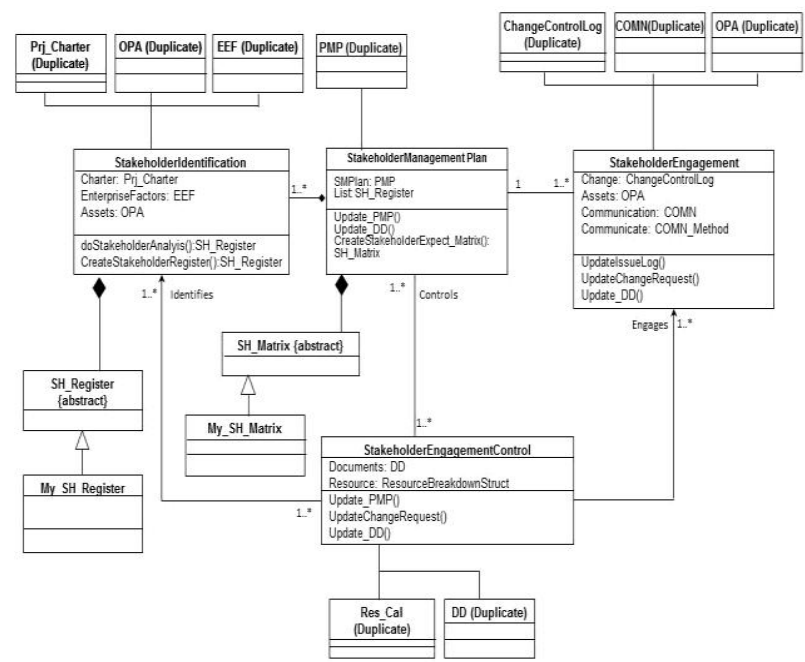

Figure 6: Project Stakeholder Management

Project manager should do the stakeholder analysis to identify the stakeholder and create a register to document their roles and responsibilities. This would help a project manager to manage stakeholders, communications and sharing information among different stakeholders. Expectations of stakeholders are captured in StakeholderExpect_Matrix.

The Issuelog, ChangeRequest document, and DeliverableDocuments (DD) are updated along with overall Project Management Plan. The Stakeholder Expectation Matrix is created initially during the Plan stage to:

- Identify all stakeholder groups.

- Document stakeholder roles and responsibilities.

- Document key representatives within each stakeholder group.

- Understand stakeholder goals and expectations.

- Document any initial perceived risks, constraints, and concerns.
- Agree on a decision-making process to be used going forward.

- Agree on an approach to gaining stakeholder commitment.

- Understand the level of influence each stakeholder has on the project.

- Ensure that goals and expectations are consistent with the proposed solution.

- Agree to proceed with planning activities.

- SH_Register is created in this process and is used in others.

\begin{tabular}{|c|c|}
\hline $\begin{array}{l}\text { PMBOK[1] } \\
\text { processes and } \\
\text { activities } \\
\text { (section) }\end{array}$ & Formalised Model \\
\hline $\begin{array}{l}\text { Identify } \\
\text { Stakeholders } \\
(13.1 .1 \\
13.1 .3)\end{array}$ & $\begin{array}{l}\text { StakeholderIdentification class } \\
\text { Operations: } \\
\text { doStakeholderAnalysis():SH_Registe } \\
\text { r } \\
\text { CreateStakeholderRegister():SH_Reg } \\
\text { ister }\end{array}$ \\
\hline $\begin{array}{l}\text { Plan } \\
\text { Stakeholder } \\
\text { Management } \\
(13.2 .1 \\
13.2 .3)\end{array}$ & $\begin{array}{l}\text { StakeholderManagementPlan class } \\
\text { Operations: } \\
\text { Update_PMP() } \\
\text { Update_DD() } \\
\text { CreateStakeholderExpect_Matrix():S } \\
\text { H_Matrix }\end{array}$ \\
\hline $\begin{array}{l}\text { Manage } \\
\text { Stakeholder } \\
\text { Engagement } \\
(13.3 .1 \quad- \\
13.3 .3)\end{array}$ & $\begin{array}{l}\text { StakeholderEngagement class } \\
\text { UpdateIssueLog() } \\
\text { UpdateChangeRequest }() \\
\text { Update_DD }()\end{array}$ \\
\hline $\begin{array}{l}\text { Control } \\
\text { Stakeholder } \\
\text { Engagement } \\
(13.4 .1 \quad- \\
13.4 .3)\end{array}$ & $\begin{array}{l}\text { StakeholderEngagementControl class } \\
\text { Operations: } \\
\text { Update_PMP() } \\
\text { UpdateChangeRequest() } \\
\text { Update_DD() }\end{array}$ \\
\hline
\end{tabular}

\begin{tabular}{|c|c|}
\hline Identify & StakeholderIdentification class \\
\hline Stakeholders & Operations: doStakeholderAnalysis(): \\
\hline$(13.1 .1 \quad-$ & SH_Register CreateStakeholder \\
\hline 13.1.3) & Register():SH_Register \\
\hline
\end{tabular}

doStakeholderAnalysis()

Identify Key Sponsors, Users, and Other Stakeholders

Identify and document all stakeholder groups and key representatives within each group. The term "stakeholder" is much broader than the term "sponsor."

Though not a complete list of responsibilities, stakeholders typically include groups or individuals who complete the following:

- Sponsor the project

- Generate, review, and approve Requirements

- Participate in the decision making process

- Develop the application (e.g., project team members)

- Use the application 
- Are affected by the application

- Support the application.

Key representatives from each stakeholder group are documented in Stakeholder Goals and Expectations template.

While creating the list of all stakeholders, identify key stakeholders who significantly influence the project. For example, key stakeholders can include the following:

- The project sponsor who provides the budget and is ultimately responsible for the project's success

- A user who generates Requirements and serves as a liaison between the project and end users.

- Other stakeholders who are affected by the new application such as end users, the client's customers, operations and support personnel, etc.

\section{CreateStakeholderRegister()}

Following the list created above, interview the key stakeholders to ensure the list is complete, that there are no missing stakeholders, and to document key characteristics about each stakeholder group and key representative.

Try to understand which stakeholders are enthusiastic supporters of the project and which ones may not be as supportive. Examples of the questions to ask to better understand the stakeholders include the following:

- End users. Is the audience comprised of primarily internal or external users? Address different security issues depending on the location where the audience accesses the application. The project needs to separate internal and external users.

- Support resources. Who provides long-term application and infrastructure support?

- Determine user authentication and authorization. Does the audience come from the same department? What are the profiles of these users? The answer to this question helps determine how to authenticate users and authorize their access to information and business applications. The answer also clarifies if roles are required and how many. The magnitude of the target audience that the application expects to reach determines how many network and system resources are needed.

- Define the functionality for the audience. What functionality does the audience need? Are they primarily information users? Are there business transactions? Do they publish and collaborate on information with others?

- Define the level of access. Does the audience share common resources equally, or are controls over content/data and application access varied among users? Fine-grained access controls involve more implementation and ongoing maintenance cost, while common resources require user authentication only.

- Identify the content. Does the audience view content/data using the same frame of reference, or do different audiences require a different taxonomy and navigational cues? This answer affects implementation both for the application user interface design and for the content classification and search technologies.

- Identify the dependencies. What enterprise applications are critical to the business process? How are these applications exposed in the application? Whether applications support XML input/output or browserbased interfaces determines how much work is required to modify the applications accessed through the application.

\begin{tabular}{|l|l|}
\hline Plan & StakeholderManagementPlan class \\
Stakeholder & Operations: \\
Manageme & Update_PMP() Update_DD() \\
nt (13.2.1 - & CreateStakeholderExpect_Matrix():S \\
13.2.3) & H_Matrix \\
\hline
\end{tabular}

\section{CreateStakeholderExpect_Matrix()}

\section{Understand Vision and Business Objectives}

Review the vision and business objectives as documented in the Project Statement of Work with the stakeholders. Ensure a common understanding. The vision depicts the stakeholders' view of the application to be developed, in terms of their key needs and features. It contains an outline of the envisioned high-level Requirements and serves as the contractual basis for the more detailed product Requirements. Obtain information on the client's vision and business objectives to understand the business rationale for the project.

- Understand (in their terms) the business problems that they face and the business results they want to achieve with the application.

- Analyze if the vision and business objectives are realistic, given the state of the business and organization.

- Recognize the business measures that the client uses to determine if the new application accomplishes the business objectives. The project drives these business measures to implemented metrics.

\section{Confirm Target Business Processes}

Identify the target business processes in the form of a Business Process Blueprint, a high-level view of the key business processes. Once documented, confirm these target business processes with the stakeholders to ensure they are relevant and accurate. This initial Business Process Blueprint serves as the basis for the Identify Major Business Processes step within Define High-level Requirements and for creating the Business Process Blueprint. In this step, projects typically perform one or two levels of process decomposition where all processes are documented.

\section{Confirm Expectations}

Agree on what sponsors want from the application (in terms of business results and personal agendas), and ensure their goals and expectations are consistent with what they say the organization should achieve. Ensure their expectations are realistic and achievable. Map expectations against the current capability. 
Confirm expectations around ongoing application support. Document the goals and expectations, including those for application acceptance and operational readiness in Stakeholder Goals and Expectations.

\section{Confirm Commitment Level}

Ensure the sponsor and other key stakeholders understand what it takes to achieve the business goals. Communicate what type of support the project needs, and agree on the actions that the sponsor takes to support the project. This includes securing resources for the project either as part of the project team or providing access to the client's personnel who own critical project information.

Document the agreed-upon stakeholder roles and responsibilities in Stakeholder Goals and Expectations. Stakeholder and client responsibilities may include the following:

- Project planning and execution

- Requirements development

- Requirements management

- Project monitoring and control

- Configuration management

- Quality assurance

- Verification

- Validation

- Supplier agreement management

- Etc.

\section{Document Stakeholder Goals and Expectations}

Review the Stakeholder Goals and Expectations with the stakeholders, and update it as required. Reflect these goals and expectations in the Business Case. Work closely with the people responsible for developing the Business Case to ensure they understand the full scope and implications of the information gathered from activities performed in this task. Clarify the types and frequency of communication that the stakeholders are expecting, and record this information in the Project Communications Plan.

\begin{tabular}{|l|l|}
\hline Manage Stakeholder & StakeholderEngagement class \\
Engagement (13.3.1 & Operations: \\
$-13.3 .3)$ & UpdateIssueLog() \\
& UpdateChangeRequest() \\
& Update_DD() \\
\hline
\end{tabular}

This deliverable documents stakeholder wants in terms of business results and priorities. The deliverable addresses goals, priorities, timelines, constraints, performance measures, roles, and responsibilities, and should be completed before proceeding with detailed planning. A cursory, yet accurate, understanding of these areas builds the foundation for further program/project planning, and subsequent in-depth gathering of all program/project stakeholders' expectations.

Goals and expectations should be documented relative to (but not limited to) the following:

- Initial assumptions for planning

- Business goals of the application
- Timing to achieve solution (i.e., target dates)

- Working relationships between the development team, business units, users, etc.

- Customer experience

- Financial targets

- Deliverables strategy (what deliverables are needed and when)

- Constraints to be accommodated

- Benefits that have been promised to Stakeholder

- Measures of success

- Communications

- Decision process

During project planning, confirm that all Stakeholder goals and expectations are addressed. If a goal or expectation can not be met, document the discrepancy in the project's issue log. The project manager should be prepared to answer how the Stakeholder goals and expectations were addressed during Quality Assurance (QA) reviews as documented in the Quality Management Plan.

As the Stakeholder Goals and Expectations are updated, the Project Communications Plan must be updated. Tailor communications based on the communication needs of various Stakeholder groups.

Reference and update this document throughout the project to manage expectations.

\begin{tabular}{|l|l|}
\hline Control & StakeholderEngagementControl \\
Stakeholder & class \\
Engagement & Operations: \\
$(13.4 .1-13.4 .3)$ & Update_PMP() \\
& UpdateChangeRequest() \\
& Update_DD() \\
\hline
\end{tabular}

During project planning, confirm that all Stakeholder goals and expectations are addressed. If a goal or expectation cannot be met, document the discrepancy in the project's issue log. The project manager should be prepared to answer how the Stakeholder goals and expectations were addressed during Quality Assurance (QA) reviews as documented in the Quality Management Plan.

As the Stakeholder Goals and Expectations are updated, the Project Communications Plan must be updated. Tailor communications based on the communication needs of various Stakeholder groups.

Reference and update this document throughout the project to manage expectations.

\section{OBJECT MODEL FOR PROJECT STAKEHOLDER MANAGEMENT}

Please find below one of the instances of the Project Closing Process Group: 


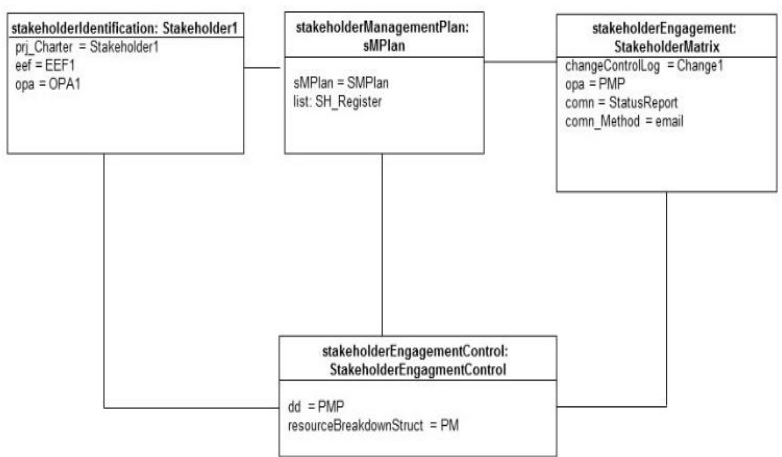

Figure 7: Object model of Project Stakeholder Management

\section{CASE STUDY}

The project was to implement an Anti-Money Laundering (AML) Solution at low cost for one of the financial institutions. The above processes are applied for managing the project effectively and efficiently.

Using PMBOK activity diagram, Fig.3 as basis, the activity diagram as shown in Fig.8 for Anti-Money laundering solution was developed.

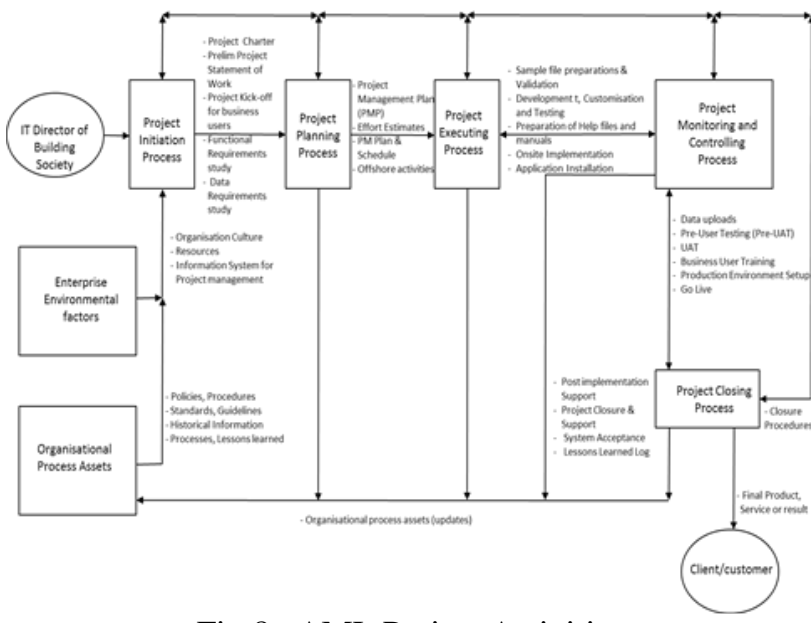

Fig.8 : AML Project Activities

The above plan was implemented as per the project high level project Gantt chart shown in Fig. 9. The team was brought onsite for gathering various requirements that is high-level, application, product requirements, technical architecture and defining the final scope of the solution.

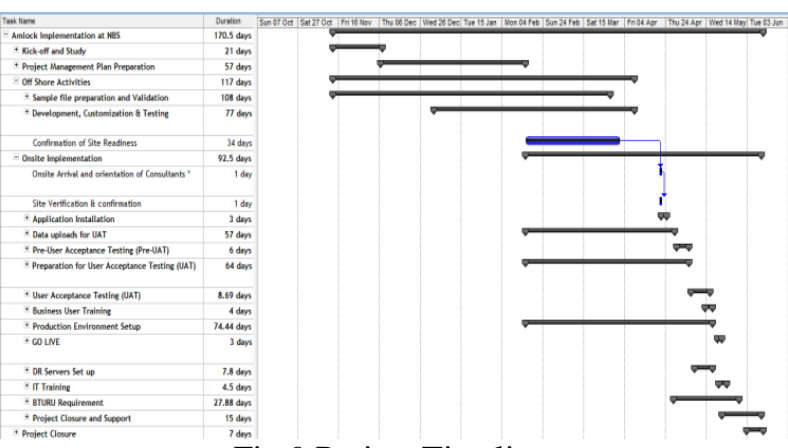

Fig.9 Project Timeline
The team on conduct of study went offshore and started customising the solution as per the requirements and developing new modules. The team was managed by the programme manager from UK and onsite project manager and technical architect. Weekly status meetings were planned with all the stakeholders who were responsible for execution of the project. Status reports were sent to all the business sponsors and stakeholders to apprise them of the progress of the project and highlighting various key deliverables and milestones achieved, and also forecasting possible risks and preventive or corrective actions taken. The product was developed and tested with sample data offsite and found that that the solution is meeting the requirements as defined in the scope and tested by client stakeholders. The implementation team was brought onsite for the final implementation and handover of the solution. Steps were taken for integration and data sharing of the client application and the new solution. Various tests were performed and parallel run of the application was taken to check the authenticity and correctness of the data and reports.

The client team signed the approval of the solution and the site went live on the date as planned. Making a good project management plan and monitoring it closely along with the involvement of all the stakeholders from the client side and solution provider side, and managing various communication channels along with the effective change management and risk management plan made the project a huge success.

All the requirements and processes of the Anti-Money Laundering solution are shown in Fig 10 and 11.

They are based on the formalised models with blue dotted boxes showing the link to the model/ class name.

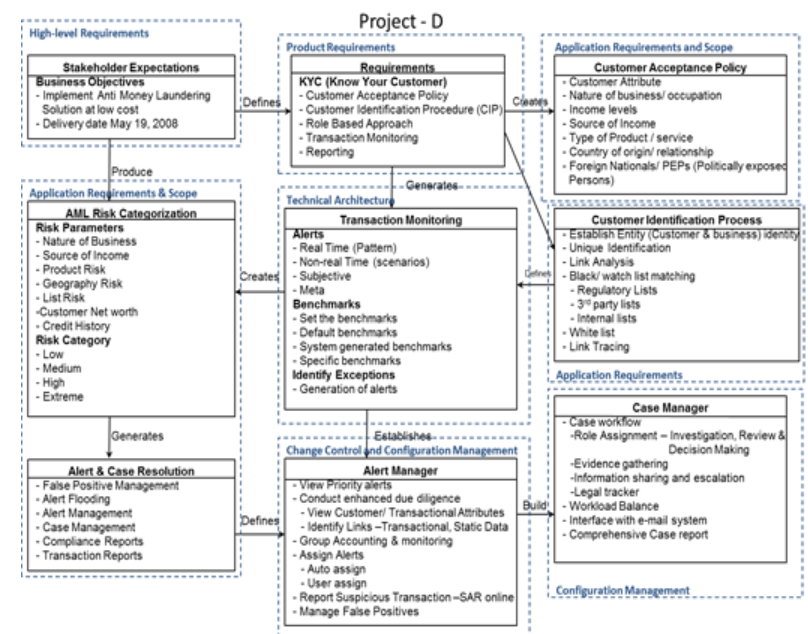

Fig 10 Processes and Requirements in AML solution

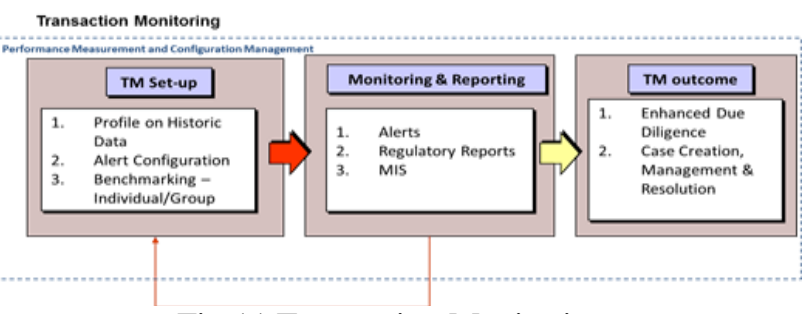

Fig 11 Transaction Monitoring 


\section{FIT GAP ANALYSIS FOR PROJECT CLOSING PROCESS GROUP}

Please find below in Fig.12 the snapshot of the Fit/Gap analysis done on the Project Closing Process Group and Project Execution Group.

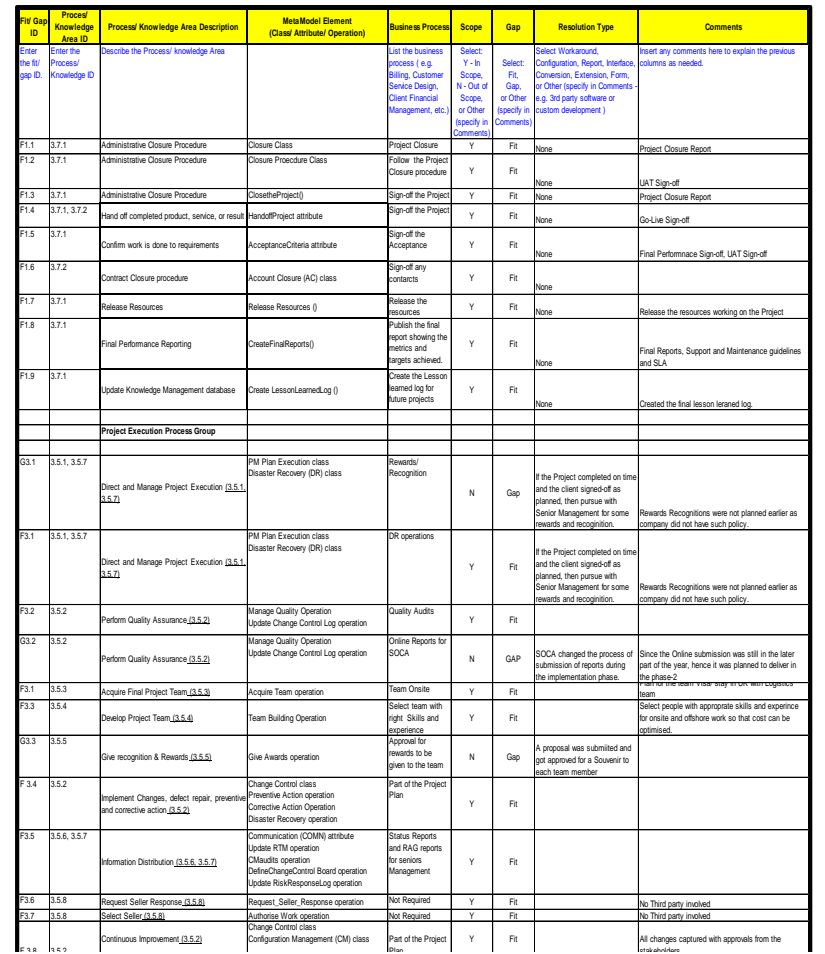

Fig.12 Snapshot of the Fit Gap Analysis for Project Closing Process Group

The analysis of Fit/ Gap for Project Closing Process Group shows that this project followed $100 \%$ of the steps/ activities as listed in the PMBOK and formalised model.

The analysis of Fit/ Gap for Project Execution Process Group shows that this project followed 9 out 12 of the steps/ activities as listed in the PMBOK and formalised model Out of the rest 3 steps, one step was of the requirement change proposed by external agency during the execution phase of the project. This change has the time period for go-live, therefore a plan was prepared, approved/ signed-off to implement the change of online reports of SOCA. The other 2 steps for rewards and recognition were proposed and got approved after the project successfully went live on the same date as planned. The project had been a tremendous success with IT Director's remark that in his 20 years of career, this is the only project which has gone live on the same day as promised in the plan. His observation was that there were some projects which finished close (2 -3 weeks later) to the planned date but not the on the same date as mentioned in the project management plan.

\section{LESSON LEARNED LOG}

Please find below the example/ sample of the lesson learned $\log$.

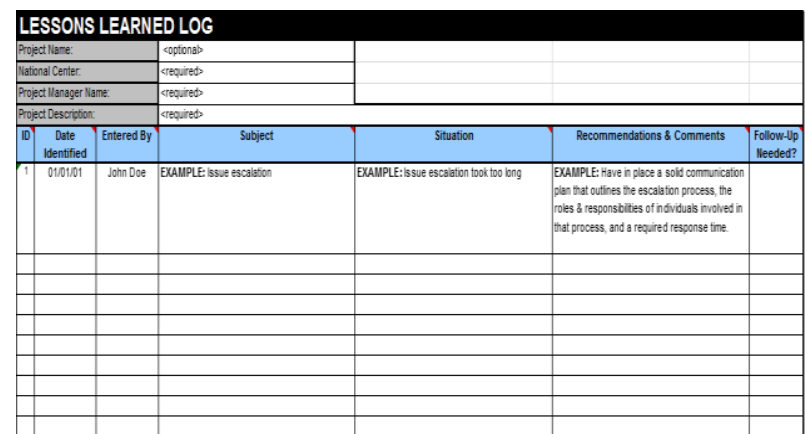

Fig.13 Snapshot of the Sample Lesson Learned Log

We created the Lesson Learned log, so that other projects can benefit from the way this project got success. This was shared on the company knowledge base and news / blog so that people can read about the project and the knowledge.

\section{CONCLUSIONS}

This is a unique attempt to define and describe a complete PM standard taking into consideration all the process and knowledge management areas for creating model driven project management using PMBOK as the base. The paper describes how UML and OCL can be used to create class diagram metamodels for project management.

Earlier research focused on simple models or one process or knowledge management area and did not make use of model driven UML and OCL concepts. These research papers focussed on creating structured flow models rather than object models.

Model driven project management helps to define various deliverables and documents in various processes areas. This will help to ensure the consistency of the plan and of the various deliverables required across multiple projects. The model will be reusable and will help to ensure that projects can be managed effectively and efficiently.

A case study of one of the projects has shown that projects can be implemented as per plan when a correct model and plan is defined. Appreciation from the client stakeholder is a testimony in this regard that when the models are defined correctly, projects can be implemented efficiently. Some deliverables and documents may vary from one project to another project as the requirements are different for different projects but the overall model will remain same. This will be a great help to all the project management professionals and also to various stakeholders of the project.

\section{REFERENCES}

[1] A Guide to the Project Management Body of Knowledge, $5^{\text {th }}$ edition, PMI, USA, 2013

[2] Managing Successful Projects with PRINCE2, OGC, UK, 2009

[3] P3M3-Portfolio, Programme and Project Management Maturity Model, OGC, UK, 2008

[4] Singh, Ravinder; Lano, Kevin, "Literature Survey of previous research work in Models and Methodologies in Project Management", International Journal of Advanced Computer Science and Applications (IJACSA), Vol. 5, No. 9, Sept 2014

[5] Singh, Ravinder; Lano, Kevin, "Defining and Formalising Project Management Models and Processes", IEEE Science and 
Information (SAI) Conference 2014, August 27-29, 2014, London U.K, pp 720-731

[6] Singh, Ravinder; Lano, Kevin, "Development Process Patterns for Distributed Onshore/Offshore Software Projects", International Journal of Advanced Computer Science and Applications (IJACSA), Vol. 5, No. 6, June 2014, pp 70-88

[7] Singh, Ravinder; Lano, Kevin, Maroukian, Krikor, "Model driven Business Process Engineering”, Bentham Science, May 2014

[8] Ur Rehman, A., "Software Project Management Methodologies/ Frameworks Dynamics - A Comparative Approach", International Conference on Information and Emerging Technologies, ICIET 2007, Pakistan, 2007, pp 1-5

[9] Schweyer, B., "Formal Specifications For A Project Management Approach", IEEE International Conference on Systems, Man and Cybernetics", Canada, 1995, vol.2, pp 1170-1175

[10] Cederling, U.; Ekinge, R.; Lennartsson, B.; Taxen, L.; Wedlund, T., "A Project Management Model Based On Shared Understanding", Proceedings of the 33rd Annual Hawaii International Conference on System Sciences, Sweden, 2000

[11] Bailetti, A.J.; Callahan, J.R.; DiPietro, P., "A Coordination Structure Approach To The Management Of Projects", IEEE Transactions on Engineering Management, 1994, vol. 41, pp 394403

[12] Milosevic,D.Z, "Standardizing Unstandardized Project Management", IEEE Technical Applications Conference, Northcon/96, USA, 1996, pp $12-17$

[13] G. Rodrigues, Dr. Alexandre, "Managing and Modelling Project Risk Dynamics A System Dynamics-based Framework", 4th European PMI Conference, London, 2001, pp 1-7

[14] Silva, C. A.; Ferrão, Paulo, "A Systems Modelling Approach to Project Management: The Green Islands Project example”, Second International Symposium on Engineering Systems, Massachusetts, 2009, pp 1-12

[15] Lin, Jyhjong; Yeh, Chunshou, “An Object-Oriented Formal Model For Software Project Management", Sixth Asia Pacific Software Engineering Conference, (APSEC '99), 1999, pp 552-559

[16] Ashman, R., "Project Estimation: A Simple Use-Case-Based Model", IT Professional, vol. 6 , Issue: 4, 2000, pp 40-44

[17] Walt Scacchi, "Process Models in Software Engineering", Encyclopaedia of Software Engineering, 2nd Edition, John Wiley and Sons, 2001

[18] Reddy, N.G., "Designing Software Project Management Models Based on Supply Chain Quality Assurance Practices", WRI World Congress on Computer Science and Information Engineering, USA, 2009, pp $659-663$

[19] Shlaer, Sally; Grand, Diana; Mellor, Stephen J., "The Project Matrix: A Model for Software Engineering Project Management", 3rd Software Engineering Standards Application Workshop (SESAW III), 1984, USA, pp 1-10

[20] Callegari, D.A.; Bastos, R.M., "Project Management and Software Development Processes: Integrating RUP and PMBOK", International Conference on Systems Engineering and Modeling, ICSEM '07, 2007, Israel, pp 1-8

[21] Hewagamage, Champa; Hewagamage, K. P., "Redesigned Framework and Approach for IT Project Management", International Journal of Software Engineering and Its Applications, vol. 5 No. 3, July, 2011, pp 89-106

[22] Van Wyngaard, C.J.; Pretorius, H.C.; Pretorius, L., "Strategic Management Of The Triple Constraint Trade-Off Dynamics - A Polarity Management Approach", IEEE International Conference on Industrial Engineering and Engineering Management (IEEM), 2011, pp $824-828$

[23] Sarantis, D.; Askounis, D.; Smithson, S., "Critical appraisal on project management approaches in e-Government", 7th International Conference on ICT and Knowledge Engineering, 2009, pp 44-49

[24] Aguirregoitia, Amaia; Javier Dolado Cosín, José;, Presedo, Concepción, "Software Project Visualization Using Task Oriented Metaphors", Journal of Software Engineering \& Applications, vol 3, 2010, pp 1015-1026

[25] C Nienaber, Rita; Barnard, Andries, "A Generic Agent Framework to Support the Various Software Project Management Processes", Interdisciplinary Journal of Information, Knowledge, and Management, vol. 2, 2007, pp 149-162
[26] Xu , Shuobo; Xu, Dishi, "Project Management Methodologies: Are They Sufficient To Develop Quality Software" 2nd IEEE International Conference on Emergency Management and Management Sciences (ICEMMS), China, 2011, pp 175-178

[27] Gilbert, M.G., "A Systems Management Approach To Improving Performance And Reducing Risks In Research Projects And Programs", IEEE Aerospace Conference Proceedings, vol. 7, 2002, pp 3467-3471

[28] Dingyong, Tang; Yizhen, Tao; Long, Jiang; Zheng, Cheng, "Application Research of Knowledge Management in R\&D Enterprise Project Management", International Conference on Information Management, Innovation Management and Industrial Engineering, vol. 4, 2009, pp 447-452

[29] White, Diana; Fortune, Joyce, "Current Practice in Project Management-an Empirical Study", International Journal of Project Management, 2002, pp 1-11

[30] Chen, L.Y.; Cian Hui Kao, "The Effects Of Strategic Implementation Of Project Management And Performance", 2nd IEEE International Conference on Information Management and Engineering (ICIME), 2010, China, pp 194-198

[31] Dekkers, C.; Forselius, P., "Increase ICT Project Success with Concrete Scope Management", 33rd EUROMICRO Conference on Software Engineering and Advanced Applications, Germany, 2007, pp 385-392

[32] Berander, P.; Wohlin, C., "Identification of Key Factors in Software Process Management - A Case Study", International Symposium on Empirical Software Engineering, Italy, 2003, pp 316-325

[33] Othman, Marini; Mohd Zain, Abdullah; Razak Hamdan, Abdul, "A Review On Project Management And Issues Surrounding Dynamic Development Environment Of ICT Project: Formation Of Research Area", International Journal of Digital Content Technology and its Applications, vol. 4, no. 1, 2010, pp 96-105

[34] Attarzadeh, Iman, "Modern Project Management: Essential Skills and Techniques", Communications of the IBIMA, vol. 2, 2008, pp 1-9

[35] Jugdev, K.; Mathur, G.; Fung, Tak; "Project Management Assets And Project Management Performance: Preliminary Findings", Technology Management in the Energy Smart World (PICMET), USA, 2011, pp 1-7

[36] Ghasemabadi, M.A.; Shamsabadi, P.D., "Application Of Five Processes Of Project Management Based On PMBOK-2008 Standard To Run EPM-2010 Project Management System: A Case Study Of Arya Hamrah Samaneh Co.”, 2nd IEEE International Conference on Emergency Management and Management Sciences (ICEMMS), 2011, China, pp 792-795

[37] Pan, G.; Pan, S.L.; Newman, M., "Managing Information Technology Project Escalation and De-Escalation: An ApproachAvoidance Perspective", IEEE Transactions on Engineering Management, vol. 56, Issue: 1, 2009 , pp 76-94

[38] Deutsch, M.S., "An Exploratory Analysis Relating The Software Project Management Process To Project Success", IEEE Transactions on Engineering Management, vol. 38 , Issue: 4, pp 365-375

[39] Feng, Li; Junyin, Wei, "A Fuzzy Approach for the Project Management", International Conference on Wireless Communications, Networking and Mobile Computing, WiCom2007, China, 2007, pp 5180-5183

[40] Zwikael, O.; Smyrk, J., "An Engineering Approach For Project Scoping”, IEEE 18th International Conference on Industrial Engineering and Engineering Management (IE\&EM), 2011, China, pp 2135-2137

41] Wetekamp, W., "Net Present Value (NPV) As A Tool Supporting Effective Project Management", IEEE 6th International Conference on Intelligent Data Acquisition and Advanced Computing Systems (IDAACS), Czech Republic, 2011, pp 898900

42] Hoon Kwak, Young; T. Anbari, Frank, "Analyzing Project Management Research: Perspectives From Top Management Journals", International Journal of Project Management, 2009, pp 435-446

[43] Hossein Fazel Bakhsheshi, Amir; Rashidi Nejad, Safoora, "Impact of Project Managers' Personalities on Project Success in Four Types of Project", 2nd International Conference on Construction and Project Management, IPEDR-2011, Singapore, vol.15, 2011, pp $181-186$ 
[44] Liu, Shuangqin; Liu, Cheng, "Management Innovation of IT Project Managers", International Conference on Information Management, Innovation Management and Industrial Engineering (ICIII), China, 2010, vol. 3, pp 62-65

[45] Muller, R.; Geraldi, J.; Turner, J.R., "Relationships Between Leadership and Success in Different Types of Project Complexities", IEEE Transactions on Engineering Management, vol. 59 Issue: 1,2012 , pp $77-90$

[46] Tatnall, A.; Shackleton, P, "IT Project Management: Developing On-Going Skills In The Management Of Software Development Projects", International Conference on Software Engineering: Education and Practice(SE:EP'96), USA, 1996, pp 400-405

[47] Armstrong, D.; Cole, P., "Managing Distances And Differences In Geographically Distributed Work Groups" in P. Hinds \& S. Kiesler (ed.) Distributed work, MIT Press, 2002, pp. 167-186

[48] Salger, F.; Englert, J.; Engels, G., "Towards Specification Patterns for Global Software Development Projects - Experiences from the Industry", 7th International Conference on the Quality of Information and Communications Technology (QUATIC), Portugal, 2010 , pp 73-78

[49] Salger, F.; Sauer, S.; Engels, G.; Baumann, A., "Knowledge Transfer in Global Software Development - Leveraging Ontologies, Tools and Assessments", 5th IEEE International Conference Global Software Engineering (ICGSE), USA, 2010, pp 336-341

[50] Narayanan, Sidharth; Mazumder, Sumonta; R., Raju, "Success of Offshore Relationships: Engineering Team Structures", International Conference on Global Software Engineering, ICGSE'06, USA, 2006, pp 73-82

[51] Persson, J.S.; Mathiassen, L.; Boeg, J.; Madsen, T.S.; Steinson, F., "Managing Risks in Distributed Software Projects: An Integrative Framework", IEEE Transactions on Engineering Management, vol. 56, Issue: 3, 2009 ,pp 508-532

[52] Khan, H.H.; Malik, N.; Usman, M.; Ikram, N., "Impact Of Changing Communication Media On Conflict Resolution In Distributed Software Development Projects", 5th Malaysian Conference in Software Engineering (MySEC), Malaysia, 2011, pp 189-194

[53] Lane, M.T.; Agerfalk, P.J., "Experiences in Global Software Development - A Framework-Based Analysis of Distributed Product Development Projects", 4th IEEE International Conference on Global Software Engineering, ICGSE, Ireland, 2009, pp 244 248

[54] Niinimaki, T., "Face-to-Face, Email and Instant Messaging in Distributed Agile Software Development Project", 6th IEEE International Conference on Global Software Engineering Workshop (ICGSEW), Finland, 2011, pp 78 - 84

[55] Czekster, R.M.; Fernandes, P.; Sales, A.; Webber, T., "Analytical Modeling of Software Development Teams in Globally Distributed Projects", 5th IEEE International Conference on Global Software Engineering (ICGSE), Ireland, 2010, pp 287-296

[56] Bartholomew, R., "Globally Distributed Software Development Using An Immersive Virtual Environment", IEEE International Conference on Electro/Information Technology, EIT, USA, 2008, pp 355-360

[57] Hashmi, J.; Ehsan, N.; Mirza, E.; Ishaque, A.; Akhtar, A., "Comparative Analysis Of Teams' Growth In Offshore And Onshore Software Development Projects", IEEE International Conference on Management of Innovation and Technology (ICMIT), Singapore, 2010, pp 1163-1167

[58] Hinds, P.J.; Bailey, D.E., "Out of Sight, Out of Sync: Understanding Conflict in Distributed Teams", Organization Science, 2003, vol. 14 (6), pp 615-632

[59] Swan, Bret; Belanger, France; Beth Watson-Manheim, Mary, "Theoretical Foundations for Distributed Work: Multilevel, Incentive Theories to Address Current Dilemmas", IEEE 37th Hawaii International Conference on System Sciences, Hawaii, vol. 1/04, 2004, pp 1-10.

[60] Bailey, D. E.; Kurland, N. B., "A Review Of Telework Research: Findings, New Directions, And Lessons For The Study Of Modern Work", Journal of Organizational Behavior, vol.23, 2002, pp 383 400

[61] Pinsonneault, A.; Boisvert, M., "The Impacts of Telecommuting on Organizations and Individuals: A Review of the Literature", in "Telecommuting and Virtual Offices: Issues and Opportunities", Johnson, N.J., London: Idea Group Publishing, 2001, pp 163-185
[62] Pearlson, K.E.; Saunders, C.S., "There's No Place Like Home: Managing Telecommuting Paradoxes", Academy of Management Executive, vol. 15, 2001, pp 117-128

[63] Belanger, France; Beth Watson-Manheim, Mary; Jordan, D.H., "Aligning IS Research and Practice: A Research Agenda for Virtual Work," Information Resources Management Journal, vol. 15, 2002, pp. $48-70$

[64] Igbaria, M., "The Driving Forces in the Virtual Society," Communications of the ACM, vol. 42, 1999, pp 64-70

[65] Alveson, M, "Knowledge Work and Knowledge-Intensive Firms". Oxford University Press, New York, 2004

[66] Hornett, A., "The Impact of External Factors on Virtual Teams: Comparative Cases", in Pauleen, J. (ed.), "Virtual Teams: Projects, Protocols and Processes", Idea Group Publishing, UK, 2004

[67] Turkington, D., "Remote Resourcing", The Beca Infrastructure Board, Auckland 2004

[68] Bélanger, F.; Collins, R.W., "Distributed Work Arrangements: A Research Framework", The Information Society, vol 14, 1998, pp 137-152

[69] Cramton, C.D., "Attribution in Distributed Work Groups", in Hinds, P.J.; Kiesler, S. (ed.) "Distributed Work", MIT Press. London, England, 2002, pp 191-212

[70] Mohammad Jafari, M.; Ahmed, S.; Dawal, S.Z.M.; Zayandehroodi, H., "The Importance Of E-Collaboration In Smes By Project Management Approach A Review", 2nd International Congress on Engineering Education (ICEED), Malaysia, 2010, pp 100-105

[71] Grant, K.P.; Pennypacker, J.S., "Project Management Maturity: An Assessment Of Project Management Capabilities Among And Between Selected Industries", IEEE Transactions on Engineering Management, vol. 53 , 2006, pp 59-68

[72] Brookes, Naomi; Clark , Robin, "Using Maturity Models to Improve Project Management Practice", POMS 20th annual Conference, USA, 2009

[73] Hoon Kwak, Young; Ibbs, C. William , "Project Management Process Maturity (PM)2 Model", Journal of Management In Engineering, 2002, pp 150- 155

[74] Sukhoo, Aneerav; Barnard, Andries; M.Eloff, Mariki; A. Van der Poll, John, "An Evolutionary Software Project Management Maturity Model for Mauritius", Interdisciplinary Journal of Information, Knowledge, and Management, vol. 2, 2007, pp 99-118

[75] EPA Guidance for Quality Assurance Project Plans for Modelling, Office of Environmental Information, EPA QA/G-5M, USA Environment Protection Agency, 2002

[76] Organisational Project Management Maturity Model (OPM3), 2nd edition, Project Management Institute, USA, 2008

[77] IEEE standard for Software Project Management Plans, IEEE std 1058-1998, IEEE, USA

[78] CMMI for Development, Version v1.3, Software Engineering Institute Process Management Program, 2010, Carnegie Mellon University, USA, 2010

[79] CMMI for Acquisition v1.3, Software Engineering Institute Process Management Program, 2010, Carnegie Mellon University, USA, 2010

[80] CMMI for Services v1.3, Software Engineering Institute Process Management Program, 2010, Carnegie Mellon University, USA, 2010

[81] The Standard for Program Management, 2nd Edition, PMI, USA, 2008

[82] Rai, V.K.; Swaminathan, N., "Constructing Program Management Framework", 4th Annual IEEE Systems Conference, USA, 2010, pp 478-483

[83] Oliva, L.M., "Program Management Is Always Team Management", IEEE International Engineering Management Conference on Management Through the Year 2000 - Gaining the Competitive Advantage, USA, 1990, pp 53-57

[84] McFarlane, L.N.; Peck, R.J.; Janneh, B.I.; Austria, R.D.; Lark, J.W., "Development Of Simulation Games To Improve The Practice Of Program Management", Systems and Information Engineering Design Symposium, SIEDS '09, USA, 2009, pp 13-18

[85] Marcroft, K.M., "Software Program Management", IEEE National Aerospace and Electronics Conference, NAECON, USA, 1991, vol.2, pp 684-689

[86] Cakmak, M.A.; Gokpinar, E.S., "Program Management Decision Making Approach for Effective Project Management: The Web Model in an Example of Turkish Space Program”, 3rd International 
Conference on Recent Advances in Space Technologies, RAST '07, Turkey, 2007, pp 59-63

[87] Bell, D.G.; Maluf, D.A.; Gawdiak, Y.; Putz, P.; Swanson, K., "The NASA Program Management Tool: A New Vision In Business Intelligence", IEEE Aerospace Conference, USA, 2006, pp 1-7

[88] Software \& Systems Process Engineering Meta-Model Specification, OMG, 2008

[89] Business Process Model and Notation (BPMN), OMG, 2011

[90] Ruiz-Rube, Iv'an; Dodero , Juan Manuel; Palomo-Duarte, Manuel; Ruiz , Mercedes and Gawn, David, "Uses and Applications of SPEM Process Models. A Systematic Mapping Study", Journal Of Software Maintenance And Evolution: Research And Practice, 2012, pp 1-32

[91] Bendraou , Reda; Gervais, Marie-Pierre; Blanc, Xavier, "UML4SPM: A UML2.0-Based Metamodel for Software Process Modelling”, Model Driven Engineering Languages and Systems, Lecture Notes in Computer Science Volume 3713, 2005, pp 17-38

[92] Järvi, Antero, and Tuomas Mäkilä. "Observations on modeling software processes with SPEM process components." Proceedings of the 9th Symposium on Programming Languages and Software Tools. 2005, pp 1-11

[93] Combemale, B., Crégut, X., Caplain, A., \& Coulette, B., "Towards a Rigorous Process Modeling with SPEM”, In ICEIS (3), 2006, pp 530-533

[94] Van der Aalst, Wil MP, Christian Stahl, and Michael Westergaard. "Strategies for modeling complex processes using colored petri nets." Transactions on Petri Nets and Other Models of Concurrency VII, Springer Berlin Heidelberg, 2013, pp 6-55.

[95] Murata, T. Petri nets: properties, analysis and applications. Proceedings of the IEEE, 77(4), April 1989, 541-80

[96] Peterson, J.L., Petri Net Theory and the Modeling of Systems. Prentice-Hall, 1981

[97] Reisig, W \& Rozenberg, G. (eds) Lectures on Petri Nets 1: Basic Models. Springer-Verlag, 1998.

[98] The World of Petri nets: http://www.informatik.unihamburg.de/TGI/PetriNets/

\section{BIOGRAPHY}

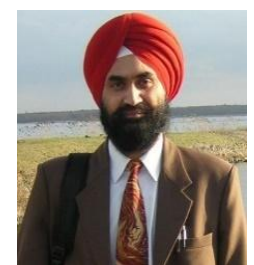

Ravinder is a research fellow at King's College, London. Ravinder has $18+$ years' experience in management, strategy and consulting within various sectors, successfully managing programmes (offshore and onshore) with budgets up to $\$ 95$ million. Ravinder has extensive experience in Programme/ Project/ process Management, Strategy Management, and Cross Cultural Awareness Management in both public and private sectors including CMMI level 5 companies, World Bank, Government of India, Defence, BFSI, Big-4 consulting, telecom and oil/utility industry. Ravinder has 2 Copyrights of software and published 13 research papers Ravinder Has been listed in Who's Who in the World 2016,2015, 2014; Who's Who In Asia 2012 \& 2006, and Who's Who in Science and Engineering 200. Ravinder has been nominated for National Award, Govt of India - Shri Dewang Mehta Award for Innovation in IT- 2003.

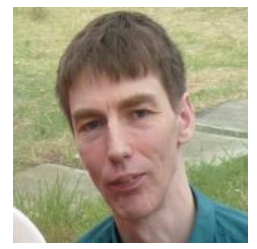

Kevin Lano is Reader in Software Engineering at King's College London. He has over 150 publications, including 8 books, in the fields of formal methods, model-driven development and verification. He is the originator of the UML-RSDS method formodel-driven development. 